\title{
Flexible bronchoscopy with moderate sedation in COPD: a case-control study
}

\author{
This article was published in the following Dove Press journal: \\ International Journal of COPD \\ 4 January 2017 \\ Number of times this article has been viewed
}

\author{
Peter Grendelmeier \\ Michael Tamm \\ Kathleen Jahn \\ Eric Pflimlin \\ Daiana Stolz \\ Clinic of Pulmonary Medicine \\ and Respiratory Cell Research, \\ University Hospital Basel, \\ Petersgraben, Basel, Switzerland
}

Correspondence: Daiana Stolz

Clinic of Pulmonary Medicine and Respiratory Cell Research, University

Hospital Basel, Petersgraben 4,

403। Basel, Switzerland

$\mathrm{Tel}+4 \mid 6 I 2655193$

Fax +4I 612654587

Email daiana.stolz@usb.ch
Background: Flexible bronchoscopy is increasingly used for diagnostic and therapeutic purposes. We aimed to examine the safety of flexible bronchoscopy with moderate sedation in patients with COPD.

Methods: This study is a prospective, longitudinal, case-control, single-center study including 1,400 consecutive patients. After clinical and lung function assessments, patients were dichotomized in COPD or non-COPD groups. The primary end point was the combined incidence of complications.

Results: The incidence of complications was similar in patients with and without COPD and independent of forced expiratory volume in the first second \% predicted. Patients with COPD more frequently required insertion of a naso- or oropharyngeal airway; however, this difference was no longer significant after adjustment for age, gender, and duration of the procedure. Hypotension was significantly more common among patients with COPD. The number of episodes of hypoxemia $\leq 90 \%$ did not differ between the groups. However, patients with COPD had a lower mean and nadir transcutaneous oxygen saturation. Transcutaneous carbon dioxide tension $\left(\mathrm{PtcCO}_{2}\right)$ change over the time course was similar in both groups, but both peak $\mathrm{PtcCO}_{2}$ and time on $\mathrm{PtcCO}_{2}>45 \mathrm{mmHg}$ were higher in the COPD group. There were no differences in patient-reported outcomes.

Conclusion: The safety of flexible bronchoscopy is similar in patients with and without COPD. This finding confirms the suitability of the procedure for both clinical and research indications. Keywords: bronchoalveolar lavage, propofol, complication, risk, respiratory insufficiency

\section{Abbreviations}

FB, flexible bronchoscopy; BAL, bronchoalveolar lavage; ASA, American Society of Anesthesiologists; $\mathrm{FEV}_{1}$, forced expiratory volume in the first second; FVC, forced vital capacity; cDLCO, diffusion capacity for carbon monoxide, corrected for hemoglobin levels; EBUS, endobronchial ultrasound; $\mathrm{PtcCO}_{2}$, transcutaneous carbon dioxide tension; $\mathrm{SO}_{2}$, transcutaneous oxygen saturation; GOLD, Global Initiative for Chronic Obstructive Lung Disease; IQR, interquartile range; ATS, American Thoracic Society; ERS, European Respiratory Journal.

\section{Introduction}

COPD is a leading cause of global morbidity and disability. COPD is predicted to become the third greatest cause of death worldwide by $2020{ }^{1}$

Patients with COPD are increasingly prone to undergo bronchoscopy for a variety of reasons. They have been typically exposed to cigarette smoking, thus sharing a major risk factor for malignancy and infection., ${ }^{2,3}$ In addition, interventional bronchoscopy has evolved as a treatment option for the disease itself (eg, bronchoscopic lung volume reduction) and its comorbidities (eg, laser and stenting placement). ${ }^{4}$ In addition, airway 
material gained by bronchoscopy is of paramount importance for translational research.

Up to now, there are scarce data examining the particularities of FB in COPD. In a randomized, placebo-controlled trial, combined sedation using an opiate and a benzodiazepine has been shown to be effective and safe in high-risk patients suffering from COPD. ${ }^{4}$ Similarly, a trial investigating the safety of bronchoscopy with endobronchial biopsy and BAL under conscious sedation using midazolam in 57 patients concluded that bronchoscopy can be performed safely in this population. ${ }^{5}$ Conversely, bronchoscopy performed under moderate sedation in patients with severe COPD was frequently associated with significant hypoventilation as detected by transcutaneous $\mathrm{PtcCO}_{2} \cdot{ }^{6}$ While current guidelines advocate caution when sedating patients with COPD, they refrain from providing specific drug recommendations. ${ }^{7,8}$ Propofol $(2.6$ di-isopropylphenol) is a sedative hypnotic frequently used in the induction and maintenance of anesthesia. Sedation with propofol can be safely performed by a non-anesthesiologist during bronchoscopy. ${ }^{9-12}$ Minor adverse events including hypoxemia and hypotension are frequent and were noted in up to one-third of patients. ${ }^{9-14}$ In a large randomized trial including 702 patients comparing conscious sedation with propofol either as bolus or as a continuous infusion, one-third of all patients suffered from COPD, although no data about the severity of disease and the prevalence of partial or global respiratory failure have been reported. ${ }^{13,15}$

The growing number of indications for elaborated diagnostic and therapeutic procedures in advanced COPD raises the question of whether flexible bronchoscopy with moderate sedation is safe in this fragile population. In light of the clinical relevance of this issue, we designed a prospective, case-control study, aiming to compare the safety of diagnostic and therapeutic flexible bronchoscopy in patients with and without COPD. The primary end point of the study was the overall incidence of complications related to the procedure.

\section{Materials and methods}

This is a prospective, longitudinal, case-control, singlecenter study performed at the Clinic of Respiratory Medicine, University Hospital Basel, a tertiary care hospital with 784 beds located in Basel, Switzerland. This study was approved by the Institutional Review Board, Ethikkommission beider Basel (EKNZ BASEC 01057).

\section{Study population and procedure variables}

All patients aged 18 or older undergoing flexible bronchoscopy using moderate sedation according to the same sedation protocol, with propofol, between January 2013 and January 2014, were considered eligible. Intubated or tracheotomized patients, those unable or unwilling to provide informed consent, those with a known allergy to propofol or undergoing a procedure repeatedly, in a location other than the bronchoscopy suite, or as an emergency were excluded (Figure 1) from the study. All patients who fulfilled the inclusion criteria were included in the study. Written informed consent for the analysis of the data was obtained from each patient before undergoing bronchoscopy.

Patients were assessed for clinical history and underwent physical examination, which included gradation of physical status in accordance with the ASA by a physician

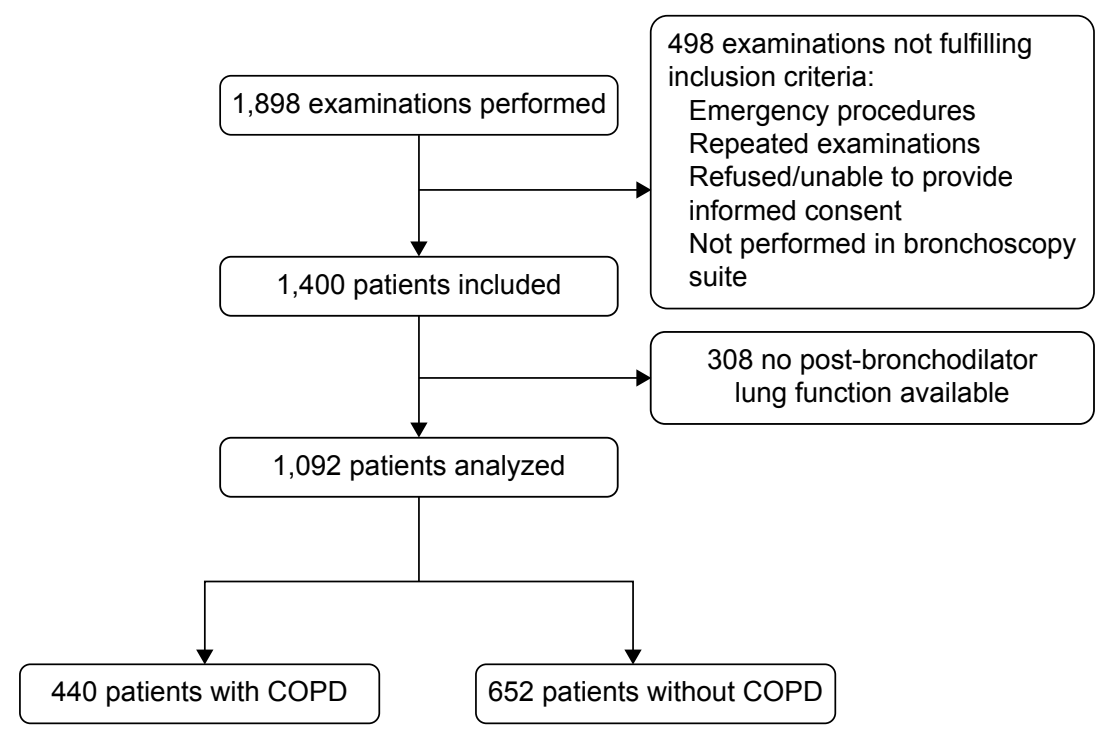

Figure I Study design. 
and a member of the nursing team trained in anesthesiology. Current medications and laboratory results including platelet counts and coagulation studies were listed. Patients were diagnosed with COPD in the presence of appropriate clinical history and physical examination, according to the GOLD recommendations. Patients presenting with an alternative, more probable diagnosis associated with the obstructive pattern $\left(\mathrm{FEV}_{1} / \mathrm{FVC}<0.7\right)$, such as asthma, sarcoidosis, hypersensitivity pneumonitis, bronchiolitis obliterans in lung transplant recipients or in patients following stem cell transplantation, widespread bronchiectasis, organizing pneumonia or respiratory bronchiolitis-associated interstitial lung disease, were not classified as COPD. Body plethysmography and diffusion capacity for carbon monoxide corrected for hemoglobin levels according to the ATS/ERS guidelines were performed within 72 hours before bronchoscopy. Moreover, blood gas analyses including partial pressure of oxygen, partial pressure of carbon dioxide, $\mathrm{pH}$, and bicarbonate were performed.

\section{Study procedure}

Bronchoscopy procedures were performed transnasally or transorally, with the patients in semi-recumbent position, by pulmonary fellow physicians under the close supervision of pulmonary attending physicians or by pulmonary attending physicians directly. Electrocardiogram, pulse oximetry $\left(\mathrm{SO}_{2}\right)$, and respiratory rate were recorded continuously during the procedure and automated non-invasive blood pressure monitoring was performed every 5 minutes. Supplemental oxygen was offered at $4 \mathrm{~L} \cdot \mathrm{min}^{-1}$ via a nasal cannula to all patients. In the case of desaturation to $\leq 90 \%$, oxygen delivery was increased to $6 \mathrm{~L} \cdot \mathrm{min}^{-1} \cdot{ }^{16} \mathrm{Nasal}$ anesthesia was achieved by $2 \%$ lidocaine gel. Bronchoscopists were advised to instill $3 \mathrm{~mL}$ aliquots of $1 \%$ lidocaine over the vocal cords and on to the trachea and both right and left main bronchi.

Patients received propofol as repeated intravenous boluses. The loading dose of propofol was titrated in order to achieve adequate initial sedation (onset of ptosis). Initially, $20 \mathrm{mg}$ of intravenous propofol, followed by a carefully titrated dose, was infused. For ASA I and II patients, the steps comprised 10-20 mg intravenous propofol, whereas for ASA III and IV, exactly $10 \mathrm{mg}$ intravenous propofol was administered based on the clinical response, as previously described. ${ }^{17}$ Between each bolus, a pause lasting $\geq 60$ seconds had to be observed. If the effect disappeared during the examination, additional intravenous boluses of $10-20 \mathrm{mg}$ propofol were given, depending on the clinical effect, in order to maintain the required level of sedation. Signs of pain or discomfort, agitation, and persistent cough were considered indicators of insufficient sedation, leading to administration of an additional dose of propofol (10-20 mg). The total dose of propofol was documented for each patient. A single dose of 4-8 mg of hydrocodone intravenously was given to all patients together with the initial bolus of propofol. ${ }^{14}$ Diagnostic procedures (ie, washings, bronchoalveolar lavage, brushing, mediastinal or peripheral transbronchial needle aspiration, endobronchial and transbronchial biopsy, EBUS) as well as therapeutic procedures (ie, laser therapy, insertion of stents, endo- or intrabronchial valves and coils) were performed upon clinical indication.

Hemodynamic monitoring, including systolic and diastolic blood pressure, heart rate, respiratory rate, oxygen saturation, and amount of oxygen supplementation required, was routinely carried out immediately before, during, and shortly after the procedure (after removal of the bronchoscope), and before transfer from the bronchoscopy suite to the recovery room, at predefined and standardized intervals. Hemodynamic parameters, including hypoxemia (any oxygen desaturation $\leq 90 \%$ ) and hypotension (any systolic blood pressure $<90 \mathrm{mmHg}$ ), procedural sedation, and duration of examination were recorded. Complications (chin lift, insertion of naso- or oropharyngeal airway, pneumothorax, minor bleeding, major bleeding, premature termination of examination, intubation, transfer to the intensive care unit, and death) were predefined, retained in a standardized, specific study form and concomitantly documented. Additionally, $\mathrm{SO}_{2}$ and $\mathrm{PtcCO}_{2}$ were assessed by a digital continuous real time monitoring system (SenTec AG, Therwil, Switzerland) in a predefined, nested cohort of 220 consecutive patients. The combined cutaneous digital sensor was placed on the ear lobe of all patients at least for 20 minutes prior to the procedure and was removed 120 minutes after the patient left the bronchoscopy suite. Physicians and endoscopy personnel were blinded for the recording of transcutaneous measured carbon dioxide and oxygen during and after the examination.

Patients were asked to rate their cough, discomfort, anxiety, and overall well-being related to the procedure as well as the willingness to undergo a repeated procedure on a numerical visual analog scale (1 [minimum] to 10 [maximum]) after full recovery, but at least 2 hours after completion of endoscopy. Patient's cough during the examination was also rated by the nursing team and the endoscopist on a similar numerical visual analog scale on completion of the procedure.

\section{Study outcome}

The primary end point of the study was the combined incidence of all predefined complications in patients with and without 
COPD. Secondary end points included the following: 1) differences in the incidence of each single complication; 2) hemodynamic parameters (systolic and diastolic blood pressure, heart rate, respiratory rate, oxygen saturation, and amount of oxygen supplementation required) on arrival at the bronchoscopy suite, initiation of sedation, 3, 6, and 9 minutes of examination, retraction of the bronchoscopy (end of the examination), and 5 minutes after the completion of the procedure; 3 ) course of $\mathrm{SO}_{2}$ and $\mathrm{PtcCO}_{2}$ during examination and at the initiation and end of examination; 4) median and peak $\mathrm{PtcCO}_{2}$; 5) median and nadir $\mathrm{SO}_{2} ; 6$ ) time with $\mathrm{PtcCO}_{2}>45 \mathrm{mmHg}$; 7) time with $\mathrm{SO}_{2}<88 \%$; and 8 ) cough during the procedure as rated by physicians and nurses, as well as patient-reported outcomes (cough, discomfort, anxiety, well-being, and readiness for a further bronchoscopic procedure).

\section{Statistical analyses}

Descriptive statistics were computed for all variables to provide means (SDs) or medians (interquartile ranges) for continuous variables and frequencies for categorical variables. Normally distributed parameters were analyzed using the Student's $t$-test for equality of means. All other continuously non-normally distributed parameters were evaluated using the non-parametric Mann-Whitney $U$ test or Kruskal-Wallis test, as appropriate. Differences in dichotomous variables were evaluated using the chi-square test or Fisher's exact test, as appropriate. The incidence of complications was analyzed as a combined end point and by single incident according to the presence and absence of COPD. Univariate and multivariate logistic regressions were used to examine the association between complications (dependent variables) and $\mathrm{FEV}_{1} \%$ predicted (independent variable) and COPD, age, gender, and duration of the procedure (independent variables). Mixed linear models were used to examine the association between hemodynamic parameters, including oxygen requirement, and transcutaneous $\mathrm{PtcCO}_{2}$ change over time course and the presence (model 1) and severity (model 2) of COPD. Dependent variables were parameter values and independent variables were time, COPD, parameter values at baseline, length of procedure, age, and the interaction "time and GOLD stage". Subject was treated as a random factor. To achieve approximate normal distribution, parameters were log-transformed. Spearman's test was used to examine the association between $\mathrm{FEV}_{1} \%$ predicted, $\mathrm{SO}_{2}, \mathrm{PtcCO}_{2}$, and $\mathrm{cDL}_{\mathrm{CO}}$. In order to analyze the effect on different outcomes, linear regression models were performed. Dependent variables were parameter values and the independent variable was COPD. Multivariate linear regression analysis was performed to examine $\mathrm{PtcCO}_{2}$ peak during bronchoscopy as the dependent factor versus $\mathrm{FEV}_{1} \%$ predicted and $\mathrm{DL}_{\mathrm{CO}}$. The Statistical Package for Social Sciences (SPSS Inc, version 21 for Windows) and R project (www.r-project.org) were used for analysis. All tests were two-tailed; a $P$-value $<0.05$ was considered significant.

\section{Results}

Demographic data are presented in Tables 1 and 2. There were significant differences between the two groups in terms of age, gender, smoking status, ASA class, and the presence of comorbidities. Similarly, patients with COPD had lower $\mathrm{FEV}_{1}$ and $\mathrm{cDLCO}$, higher total lung capacity and residual volume, and lower $\mathrm{pO}_{2}$ as compared to patients without COPD. Indication, number, and distribution of diagnostic and interventional procedures per patient and group are given in Table 3. The main reason for bronchoscopy was pulmonary infection in patients without COPD in contrast to suspicion of malignancy in patients with COPD. Accordingly, the most commonly performed diagnostic procedures were BAL (67.5\%) and bronchial washing (19.5\%), followed by endobronchial and transbronchial biopsies (15.4 and $14.7 \%$, respectively). Complex interventions, that is EBUS, stent-placement, laser application, and bronchoscopic lung volume reduction procedures, were performed in 202 cases. Almost one-third of the patients underwent two or more bronchoscopic procedures, with a similar distribution in both groups. Crude procedural sedation requirements were similar in patients with and without COPD. However, when adjusted for the duration of the examination and body weight, patients with COPD demanded significantly less propofol than patients without COPD.

\section{Complications in patients with and without COPD}

The combined incidence of complications was similar in patients with and without COPD $(P=0.301)$ and independent of $\mathrm{FEV}_{1} \%$ predicted ( $P=0.789$, Table 4$)$. Individually, the need for insertion of a naso- or oropharyngeal airway was more common in the group of patients with COPD. However, this difference was no longer significant after adjustment for age, gender, and duration of the procedure. The risk for any complication $(P=0.142)$ and the number of complications ( $P=0.113)$ observed during the procedure were similar across GOLD stages. However, patients with severe and very severe disease had an increased number of complications as compared to those with mild or moderate disease $(P=0.037)$. 
Table I Demographic data of I,092 patients undergoing flexible bronchoscopy based on the presence or absence of COPD

\begin{tabular}{|c|c|c|c|c|}
\hline Characteristics & No COPD (n=652) & COPD $(n=440)$ & Total $(n=I, 092)$ & $P$-value \\
\hline Age, years & $58.5 \pm 14.9$ & $66.5 \pm 10.2$ & $61.6 \pm 15$ & $<0.001$ \\
\hline Male, gender & $52.9 \%$ & $66.6 \%$ & $58.4 \%$ & $<0.001$ \\
\hline Height, cm & $168.3 \pm 9.4$ & $168.5 \pm 8.7$ & $160.3 \pm 9.1$ & 0.596 \\
\hline Weight, kg & $70.2 \pm 17.6$ & $70.3 \pm 17.4$ & $70.2 \pm 17.5$ & 0.715 \\
\hline $\mathrm{BMI}, \mathrm{kg} / \mathrm{m}^{2}$ & $24.7 \pm 5.3$ & $24.6 \pm 5.3$ & $24.6 \pm 5.3$ & 0.478 \\
\hline \multicolumn{5}{|l|}{ Smoking status } \\
\hline Current smoker, \% & $76(11.7 \%)$ & $109(24.8 \%)$ & 185 (I7.0\%) & \multirow[t]{2}{*}{$<0.001$} \\
\hline Ex-smoker, \% & $312(47.9 \%)$ & $294(66.8 \%)$ & $606(55.5 \%)$ & \\
\hline Pack-years, n & $27.2 \pm 25.4$ & $47.9 \pm 25.4$ & $37.9 \pm 27.4$ & $<0.001$ \\
\hline \multicolumn{5}{|l|}{ ASA class, \% } \\
\hline I & $16(2.5 \%)$ & $4(0.9 \%)$ & $20(1.8 \%)$ & \multirow[t]{4}{*}{$<0.001$} \\
\hline II & $179(27.5 \%)$ & $70(15.9 \%)$ & $249(22.8 \%)$ & \\
\hline III & $413(63.3 \%)$ & 307 (69.8\%) & $720(66.0 \%)$ & \\
\hline IV or V & $44(6.8 \%)$ & $60(13.6 \%)$ & $104(9.5 \%)$ & \\
\hline \multicolumn{5}{|l|}{ Comorbidities, \% } \\
\hline Coronary artery disease & $84(12.9 \%)$ & 84 (19.1\%) & $168(15.4 \%)$ & 0.009 \\
\hline Congestive heart failure & $4 \mathrm{l}(6.3 \%)$ & $50(11.4 \%)$ & $91(8.3 \%)$ & 0.007 \\
\hline Cerebral vascular disease & $21(3.2 \%)$ & $19(4.3 \%)$ & $40(3.7 \%)$ & 0.371 \\
\hline Diabetes mellitus & $63(9.7 \%)$ & $54(12.3 \%)$ & $117(10.7 \%)$ & 0.209 \\
\hline Renal failure & $106(16.3 \%)$ & $44(10.0 \%)$ & $150(13.7 \%)$ & 0.006 \\
\hline Liver disease & $9(1.4 \%)$ & $10(2.3 \%)$ & $19(1.7 \%)$ & 0.345 \\
\hline Solid malignant tumor & $139(21.4 \%)$ & $187(42.5 \%)$ & $326(29.9 \%)$ & $<0.001$ \\
\hline Hematological malignancy & 139 (21.4\%) & $19(4.3 \%)$ & $158(14.5 \%)$ & $<0.001$ \\
\hline Immunosuppression & $275(42.2 \%)$ & 55 (12.5\%) & $330(30.2 \%)$ & $<0.001$ \\
\hline Rheumatologic disease & $62(9.5 \%)$ & $16(3.6 \%)$ & $78(7.1 \%)$ & $<0.001$ \\
\hline HIV & $3(0.5 \%)$ & II (2.5\%) & $14(1.3 \%)$ & 0.004 \\
\hline Alcohol abuse & $14(2.2 \%)$ & $25(5.7 \%)$ & $39(3.6 \%)$ & 0.005 \\
\hline Intravenous drug use & $3(0.5 \%)$ & $4(0.9 \%)$ & $7(0.6 \%)$ & 0.205 \\
\hline \multicolumn{5}{|l|}{ Current medication, \% } \\
\hline Acetylsalicylic acid & $104(16.0 \%)$ & $129(29.4 \%)$ & $233(21.3 \%)$ & $<0.001$ \\
\hline Clopidogrel & $16(2.5 \%)$ & $10(2.3 \%)$ & $26(2.4 \%)$ & 0.850 \\
\hline Prasugrel & $3(0.5 \%)$ & I (0.2\%) & $4(0.4 \%)$ & 0.513 \\
\hline Oral anticoagulant & $45(6.9 \%)$ & $27(6.1 \%)$ & $72(6.6 \%)$ & 0.699 \\
\hline Heparin (therapeutic dose) & $6(0.9 \%)$ & $2(0.5 \%)$ & $8(0.7 \%)$ & 0.501 \\
\hline Heparin (prophylactic dose) & $16(2.5 \%)$ & 14 (32\%) & $30(2.7 \%)$ & 0.474 \\
\hline LMWH (therapeutic dose) & $7(1.1 \%)$ & $7(1.6 \%)$ & $14(1.3 \%)$ & 0.526 \\
\hline LMWH (prophylactic dose) & 74 (II.4\%) & $66(15.0 \%)$ & $140(12.9 \%)$ & 0.099 \\
\hline Sedatives & $20(3.1 \%)$ & $25(5.7 \%)$ & $45(4.1 \%)$ & 0.042 \\
\hline Hypnotics & 14 (2.2\%) & $19(4.3 \%)$ & $33(3.0 \%)$ & 0.079 \\
\hline Mean prothrombin time, $\%$ & $86.4 \pm 20.3$ & $86.5 \pm 20.0$ & $88.1 \pm 42.68$ & 0.942 \\
\hline INR & I.I (I.0-I.I) & I.I (I.0-I.I) & I.I (I.0-I.I) & 0.583 \\
\hline Mean platelet count, g/L & $263 \pm 126$ & $286 \pm 132$ & $273 \pm 129$ & 0.003 \\
\hline
\end{tabular}

Notes: Data are presented as mean \pm SD, $n(\%)$, or median (IQR). P-values represent the comparison between non-COPD and COPD groups.

Abbreviations: BMI, body mass index; ASA, American Society of Anesthesiologists; HIV, human immunodeficiency virus; LMWH, low-molecular-weight heparin; INR, international normalized ratio; IQR, interquartile range.

\section{Hemodynamic parameters and amount of oxygen requirement}

Patients with and without COPD depicted distinctive hemodynamic responses to sedation and required diverging amounts of oxygen supplementation during the procedure (Figure 2). Herein, hypotension ( $20.7 \%$ [n=135] vs $29.8 \%$ [n=131], $P<0.001)$ was significantly more common among patients with COPD, but this association was again dependent on age, gender, and the duration of bronchoscopy $(P=0.124)$. While the number of episodes of hypoxemia $\leq 90 \%$ did not differ between COPD and non-COPD $(36.2 \%$ [n=236] vs $40.9 \%$ [n=180], $P=0.125$ ), patients with COPD had a lower median and nadir $\mathrm{SO}_{2}$ and remained hypoxemic $\left(\mathrm{SO}_{2}<88 \%\right)$ longer than patients without COPD (Table 5). There was no correlation between time with an oxygen saturation $<88 \%$ or nadir $\mathrm{SO}_{2}$ during the examination and $\mathrm{FEV}_{1} \%$ predicted 
Table 2 Lung function and arterial blood gas analysis data of I,092 patients undergoing flexible bronchoscopy based on the presence or absence of COPD

\begin{tabular}{|c|c|c|c|c|}
\hline Characteristics & No COPD $(n=652)$ & COPD $(n=440)$ & Total $(n=I, 092)$ & $P$-value \\
\hline $\mathrm{FEV}_{1}$, liters & $2.25 \pm 0.92$ & $1.51 \pm 0.69$ & $1.96 \pm 0.91$ & $<0.001$ \\
\hline $\mathrm{FEV}_{1}$, \% predicted & $78.4 \pm 24.8$ & $56.9 \pm 24.4$ & $70.0 \pm 26.8$ & $<0.001$ \\
\hline FVC, liters & $3.00 \pm 1.11$ & $2.75 \pm 0.88$ & $2.90 \pm 1.04$ & $<0.001$ \\
\hline FVC, \% predicted & $85.1 \pm 22.7$ & $81.9 \pm 21.2$ & $83.9 \pm 22.1$ & 0.024 \\
\hline $\mathrm{FEV}_{1} / \mathrm{FVC}$ & $70.3 \pm 12.3$ & $49.2 \pm 15.8$ & $63.0 \pm 17.2$ & $<0.001$ \\
\hline cDLCO, \% & 7I.I \pm 24.4 & $57.4 \pm 22.7$ & $65.7 \pm 24.6$ & $<0.001$ \\
\hline RV, liters & $2.17 \pm 0.66$ & $3.36 \pm 1.27$ & $2.63 \pm 1.11$ & $<0.001$ \\
\hline RV, \% predicted & $104.8 \pm 31.0$ & $148.3 \pm 59.5$ & $121.8 \pm 49.2$ & $<0.001$ \\
\hline TLC, liters & $5.36 \pm 1.34$ & $6.42 \pm 1.55$ & $5.78 \pm 1.51$ & $<0.001$ \\
\hline TLC, \% predicted & $91.4 \pm 16.6$ & $107.6 \pm 23.4$ & $97.7 \pm 21.0$ & $<0.001$ \\
\hline RV/TLC & $41.3 \pm 11.5$ & $51.4 \pm 11.7$ & $45.27 \pm 12.6$ & $<0.001$ \\
\hline \multicolumn{5}{|l|}{ Arterial blood gas analysis } \\
\hline $\mathrm{paO}_{2}, \mathrm{mmHg}$ & $75.31 \pm 10.13$ & $67.7 \pm 12.08$ & $70.88 \pm 13.43$ & $<0.001$ \\
\hline $\mathrm{paCO}_{2}, \mathrm{mmHg}$ & $36.45 \pm 5.25$ & $38.78 \pm 6.68$ & $37.73 \pm 6.23$ & 0.196 \\
\hline $\mathrm{pH}$ & $7.43 \pm 0.04$ & $7.42 \pm 0.03$ & $7.43 \pm 0.04$ & 0.457 \\
\hline Bicarbonate, $\mathrm{mmol} / \mathrm{L}$ & $24.7 \pm 2.1$ & $25.4 \pm 2.6$ & $25.1 \pm 2.4$ & 0.068 \\
\hline
\end{tabular}

Notes: Data are presented as mean \pm SD. P-values represent the comparison between non-COPD and COPD groups.

Abbreviations: $\mathrm{FEV}_{1}$, forced expiratory volume in the first second; FVC, forced vital capacity; cDLCO, diffusion capacity for carbon monoxide, corrected for hemoglobin levels; $\mathrm{RV}$, residual volume; TLC, total lung capacity; $\mathrm{paO}_{2}$, partial pressure of oxygen; $\mathrm{paCO}_{2}$, partial pressure of carbon dioxide.

Table 3 Main indication, bronchoscopic procedures, and procedural sedation in 1,092 patients undergoing flexible bronchoscopy based on the presence or absence of COPD

\begin{tabular}{|c|c|c|c|c|}
\hline $\begin{array}{l}\text { Indication for } \\
\text { bronchoscopy }\end{array}$ & No COPD (n=652) & COPD $(n=440)$ & Total $(n=I, 092)$ & $P$-value \\
\hline Suspicion of malignancy & $113(17.3 \%)$ & $126(28.6 \%)$ & 239 (21.9\%) & $<0.001$ \\
\hline Interstitial lung disease & $93(14.3 \%)$ & $8(1.8 \%)$ & $101(9.3 \%)$ & \\
\hline Infection & $299(45.9 \%)$ & $95(21.6 \%)$ & $394(36.0 \%)$ & \\
\hline Chronic cough & $30(4.6 \%)$ & $5(1.1 \%)$ & $35(3.2 \%)$ & \\
\hline Hemoptysis & II (I.7\%) & $15(3.4 \%)$ & $26(2.4 \%)$ & \\
\hline Bronchial toilette & 40 (6.1\%) & 67 (I5.2\%) & 107 (9.8\%) & \\
\hline Stenting & $5(0.8 \%)$ & $\mathrm{II}(2.5 \%)$ & $16(1.5 \%)$ & \\
\hline Laser therapy & $9(1.4 \%)$ & $9(2.0 \%)$ & $18(1.6 \%)$ & \\
\hline Miscellaneous & $53(8.1 \%)$ & $102(23.2 \%)$ & $155(14.2 \%)$ & \\
\hline \multicolumn{5}{|l|}{ Diagnostic procedures } \\
\hline Bronchial washings & $90(13.8 \%)$ & $122(27.7 \%)$ & $212(19.4 \%)$ & $<0.001$ \\
\hline Bronchoalveolar lavage & $513(78.7 \%)$ & $226(51.4 \%)$ & 739 (67.7\%) & $<0.001$ \\
\hline Bronchial brushing & $44(6.8 \%)$ & $63(14.3 \%)$ & $107(9.8 \%)$ & $<0.001$ \\
\hline Endobronchial biopsy & $89(13.7 \%)$ & $80(18.2 \%)$ & $169(15.5 \%)$ & 0.054 \\
\hline Transbronchial biopsy & $110(16.9 \%)$ & 51 (II.6\%) & $16 \mid(14.7 \%)$ & 0.022 \\
\hline Mediastinal TBNA & $32(4.9 \%)$ & $19(4.3 \%)$ & $5 \mathrm{I}(4.7 \%)$ & 0.664 \\
\hline Peripheral TBNA & $25(3.8 \%)$ & 32 (7.3\%) & $57(5.2 \%)$ & 0.017 \\
\hline EBUS & $66(10.1 \%)$ & $38(8.6 \%)$ & $104(9.5 \%)$ & 0.420 \\
\hline \multicolumn{5}{|l|}{ Interventions } \\
\hline Laser therapy & $10(1.56 \%)$ & $9(2.0 \%)$ & 19 (1.78\%) & 0.638 \\
\hline Stenting & $5(0.8 \%)$ & $9(2.0 \%)$ & $14(1.3 \%)$ & 0.096 \\
\hline Valve implantation & I (0.2\%) & $23(5.2 \%)$ & $24(2.2 \%)$ & $<0.001$ \\
\hline Coils implantation & $0(0 \%)$ & $9(2.0 \%)$ & $9(0.8 \%)$ & 0.001 \\
\hline \multicolumn{5}{|l|}{ Number of procedures } \\
\hline $0-1$ & $433(66.4 \%)$ & $287(65.2 \%)$ & $720(65.9 \%)$ & 0.204 \\
\hline $2-3$ & $193(29.6 \%)$ & $125(28.4 \%)$ & $318(29.1 \%)$ & \\
\hline$\geq 4$ & $26(4.0 \%)$ & $28(6.4 \%)$ & $54(4.9 \%)$ & \\
\hline Propofol (total dose), mg & $229 \pm 143$ & $234 \pm 158$ & $231 \pm 149$ & 0.544 \\
\hline Propofol (dose/kg), mg/kg & $3.34 \pm 2.15$ & $3.53 \pm 2.47$ & $3.37 \pm 2.23$ & 0.219 \\
\hline Propofol (dose $/ \mathrm{kg} / \mathrm{min}), \mathrm{mg}$ & $0.275 \pm 0.173$ & $0.239 \pm 0.181$ & $0.265 \pm 0.369$ & 0.001 \\
\hline Hydrocodone, mg & $4.23 \pm 2.27$ & $4.08 \pm 2.62$ & $4.11 \pm 2.38$ & 0.477 \\
\hline Duration, minutes & $12(7-20)$ & $15(8-27)$ & $12(7-23)$ & $<0.001$ \\
\hline
\end{tabular}

Notes: Data are presented as number (\%), mean \pm standard deviation, or median (IQR). P-values represent the comparison between non-COPD and COPD groups. Abbreviations: TBNA, transbronchial needle aspiration; EBUS, endobronchial ultrasound; IQR, interquartile range. 
Table 4 Complications of flexible bronchoscopy in 1,092 patients undergoing flexible bronchoscopy according to the present or absence of COPD

\begin{tabular}{lllll}
\hline Incident & No COPD (n=652) & COPD (n=440) & Total (n=I,092) & P-value \\
\hline Chin lift & $449(68.9 \%)$ & $326(74.1 \%)$ & $775(71.0 \%)$ & 0.080 \\
Insertion of nasopharyngeal/ & $48(7.4 \%)$ & $52(11.8 \%)$ & $100(9.2 \%)$ & \\
oropharyngeal airway & & & $1(0.1 \%)$ & 0.021 \\
Pneumothorax & $0(0 \%)$ & $\mathrm{I}(0.2 \%)$ & $64(5.9 \%)$ & 0.234 \\
Minor bleeding & $46(7.1 \%)$ & $18(4.1 \%)$ & $6(0.6 \%)$ & 0.068 \\
Major bleeding & $5(0.8 \%)$ & $\mathrm{I}(0.2 \%)$ & $\mathrm{I}(0.1 \%)$ & 0.307 \\
Termination of examination & $0(0.0 \%)$ & $\mathrm{I}(0.2 \%)$ & $3(0.3 \%)$ & 0.234 \\
Intubation & $3(0.5 \%)$ & $0(0.0 \%)$ & $7(0.6 \%)$ & 0.235 \\
Transfer to intensive care unit & $6(0.9 \%)$ & $\mathrm{I}(0.2 \%)$ & 0.218 \\
Death & $0(0 \%)$ & $0(0 \%)$ & 1.000 \\
\hline
\end{tabular}

Notes: Data are presented as number (\%). P-values represent the comparison between non-COPD and COPD groups.

(rho $=0.058, P=0.543$ and rho $=-0.054, P=0.565$, respectively) or $\mathrm{cDLCO} \%$ (rho $=-0.110, P=0.093$ and $\mathrm{rho}=0.040$, $P=0.219$, respectively). The risk for hypoxemia $(P=0.117)$ and hypotension $(P=0.104)$ did not differ across GOLD stages. Collapsing GOLD stages 3 and 4 together depicted a trend toward a higher risk of hypoxemia in patients with severe or very severe disease $(P=0.055)$.

Patients with COPD had higher baseline and median and peak $\mathrm{PtcCO}_{2}$ levels. Hence, time on $\mathrm{PtcCO}_{2}>45 \mathrm{mmHg}$ was found to be increased compared to non-COPD patients. Conversely, the change in $\mathrm{PtcCO}_{2}$ over the time course of bronchoscopy was similar in patients with and without COPD $(P=0.571$, Figure 3$)$. $P_{t c C O}$ peak increased linearly across the COPD stages (median [interquartile range]: GOLD I, 51.9 [48.6-60.1] mmHg; GOLD II, 56.9 [48.4-65.8] mmHg; GOLD III, 60.3 [52.6-66.3] mmHg; and GOLD IV, 66 [52.8-79.7] mmHg; $P=0.031)$. Peak $\mathrm{PtcCO}_{2}$ correlated both with the $\mathrm{FEV}_{1} \%$ predicted value and $\mathrm{cDL}_{\mathrm{CO}}$ in $\mathrm{COPD}$ (rho $=-0.336, P<0.001$ and rho $=-0.285, P=0.004$ ) but not in non-COPD ( $P>0.05$ for both). Only $\mathrm{FEV}_{1} \%$ proved to be independently associated with peak $\mathrm{PtcCO}_{2}$ (beta coefficient $=-0.393[-0.358$ to 0.0700$], P=0.004)$ in a multivariate linear regression model including both $\mathrm{FEV}_{1}$ and $\mathrm{cDLCO}$.

\section{Cough scores and patient-reported outcomes}

Cough scores reported by patients, nurses, and physicians did not differ for patients with and without $\operatorname{COPD}(P=0.176$, $P=0.619$, and $P=0.639$ ) and correlated significantly with each other (patient/nurses: rho $=0.278, P=0.028$; patient/physician: rho $=0.261, P=0.039$; nurses $/$ physicians: rho $=0.839$, $P<0.01)$. Likewise, patients with and without COPD had similar discomfort $(0.5[0-1.5]$ vs 1.0 [0-1.5], $P=0.430)$, anxiety $(0.5[0-1.8]$ vs $1.0[0-2.0], P=0.192)$, and well-being scores $(4.0$ [2-5] vs 3.8 [2-6.1], $P=0.162)$. The readiness to undergo a further bronchoscopy was similar in both patient groups $(98.5 \%$ vs $95.7 \%, P=0.309)$.

\section{Discussion}

The present study suggests that the safety of FB with moderate sedation with propofol is comparable in patients with and without COPD. However, patients with COPD exhibit distinctive hemodynamic responses to sedation. Patients with COPD commonly developed hypotension in addition to more severe and persistent hypoxemia. Moreover, despite a similar peri-procedural increase in $\mathrm{PtcCO}_{2}, \mathrm{COPD}$ patients were exposed to more pronounced hypercapnia, mainly due to higher baseline levels as compared to their non-COPD counterparts. Thus, monitoring of the $\mathrm{PtcCO}_{2}$ levels might be warranted in patients with COPD with basal hypercapnia, severe airway obstruction, and in those requiring prolonged interventions. Other interesting findings of this study are that both operating conditions for the endoscopy team, cough scores assessed by physicians and nurses, as well as patientreported outcomes seem not to be negatively influenced by the presence of COPD. The side-effect profile of the examination confirms the suitability of flexible bronchoscopy for research sampling and supports the realization of system biology studies in matrices such as bronchoalveolar lavage and/ or endobronchial biopsies, even in patients with advanced disease. Taken together, these results strongly suggest that patients with COPD, despite their frailty, can safely benefit from complex interventions performed through flexible bronchoscopy with moderate sedation.

To our knowledge, this is by far the largest study examining the safety of flexible bronchoscopy and the only one including complex procedures in patients with COPD. We observed a similar number of peri-procedural complications in patients with and without the disease, supporting a similar safety profile of propofol in this population., ${ }^{9,10,14}$ Propofol 


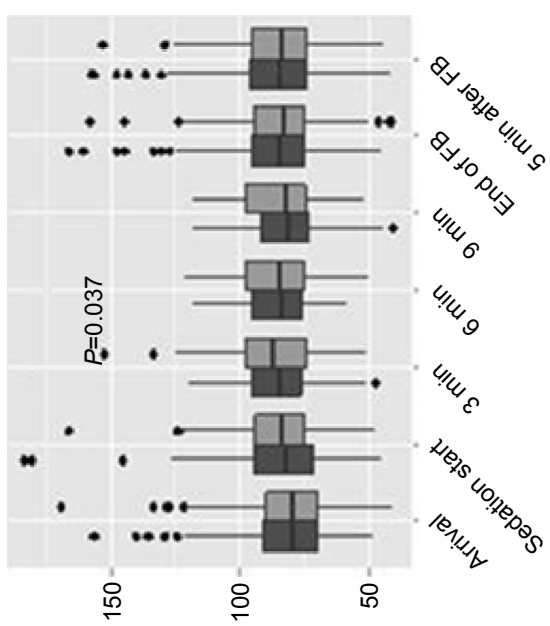

(„-u!̣ słeәq) әрел дееән

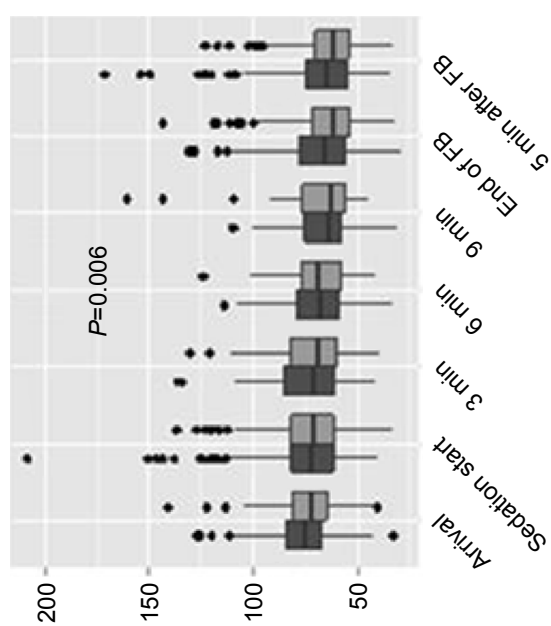

(6Нuس) da ग!|01se!

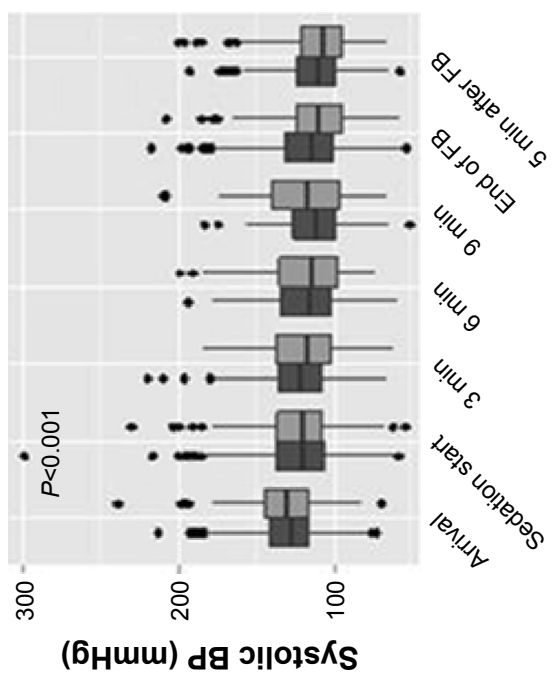

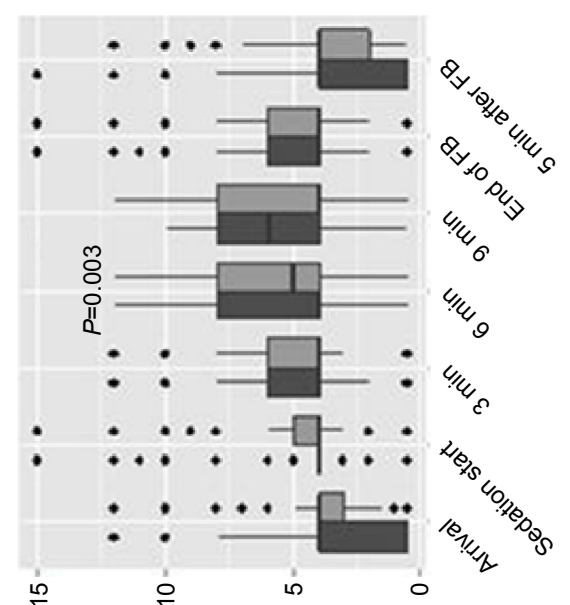

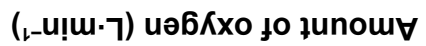

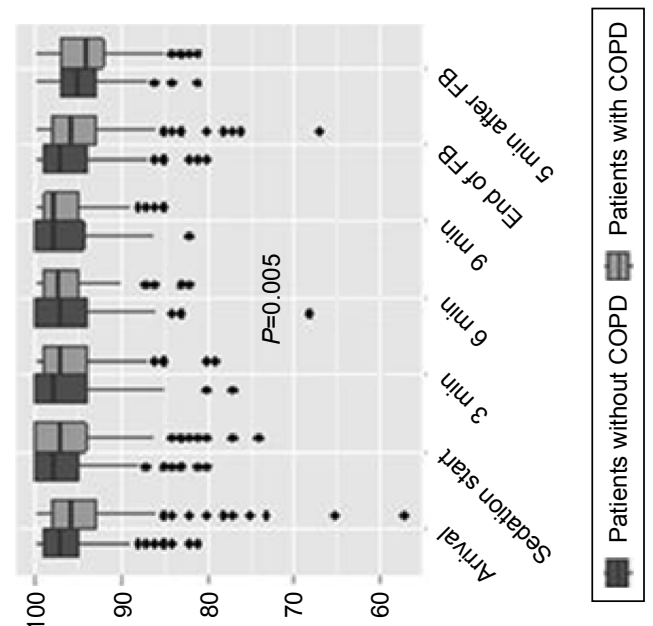

(\%) uo!łeגnłes uә6Кх0

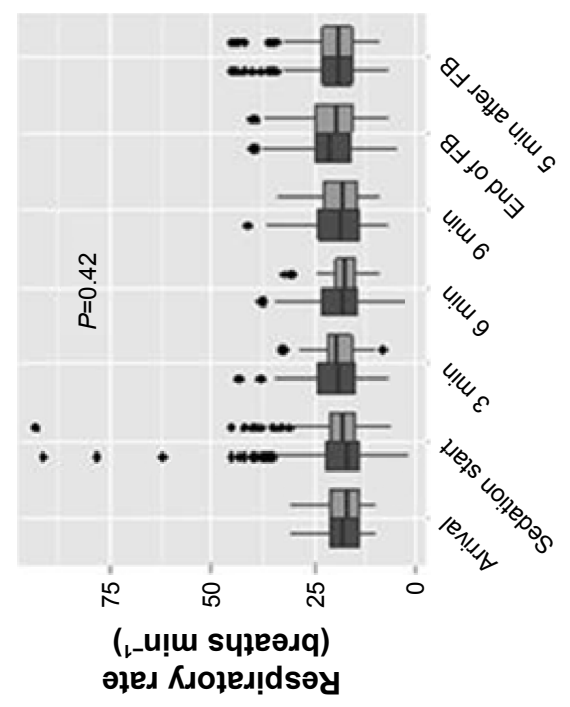

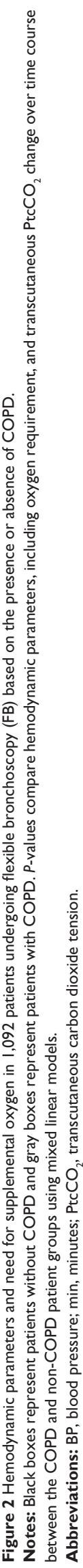


Table 5 Results of the transcutaneous, real time, continuous monitoring of the oxygen saturation and carbon dioxide tension in a nested cohort of 220 patients undergoing flexible bronchoscopy according to the presence or absence of COPD

\begin{tabular}{llll}
\hline Characteristics & No COPD (n=I I 8) & COPD (n=I 02) & P-value \\
\hline $\mathrm{SO}_{2}$, median, \% & $96(94-97)$ & $94(93-95)$ & $<0.00 \mathrm{I}$ \\
$\mathrm{SO}_{2}$ time $<88 \%$, minutes & $0.14(0-1.16)$ & $1.12(0.04-4.4)$ & $<0.00 \mathrm{I}$ \\
$\mathrm{SO}_{2}$ nadir during bronchoscopy, \% & $87(84-9 \mathrm{I})$ & $86(82-89)$ & 0.002 \\
$\mathrm{PtcCO}_{2}$ at baseline, $\mathrm{mmHg}$ & $35.2(32.1-38.3)$ & $36.7(33.8-39.1)$ & 0.036 \\
$\mathrm{PtcCO}_{2}$ median, $\mathrm{mmHg}$ & $39.5(36.5-44.7)$ & $42.5(38.7-46.2)$ & $<0.00 \mathrm{I}$ \\
$\mathrm{PtcCO}_{2}$ time $>45 \mathrm{mmHg}$, minutes & $12.0(2.1-45.4)$ & $32.9(7.0-76.2)$ & $<0.00 \mathrm{I}$ \\
$\mathrm{PtcCO}_{2}$ peak, $\mathrm{mmHg}$ & $51.9(46.1-61.7)$ & $57.9(50.3-66.1)$ & $<0.00 \mathrm{I}$ \\
$\mathrm{PtcCO}_{2}$ at end of intervention, $\mathrm{mmHg}$ & $49.2(42.0-57.0)$ & $54.5(47.0-63.0)$ & 0.003 \\
\hline
\end{tabular}

Notes: Data are presented as median (interquartile range). P-values represent the comparison between non-COPD and COPD groups.

Abbreviations: $\mathrm{PtcCO}_{2}$, transcutaneous carbon dioxide tension; $\mathrm{SO}_{2}$, transcutaneous oxygen saturation.

has proved to be an attractive option to combined sedation with midazolam and hydrocodone, providing significantly faster recovery times and improved patient satisfaction scores. ${ }^{9,10}$ It has also been shown that the combination of propofol and hydrocodone is safe, has a better cough suppressing effect, and is associated with significantly lower propofol requirements compared to propofol alone. ${ }^{14}$ The feasibility and safety of propofol sedation as administered by repeated bolus or continuous infusion is also supported by a large randomized trial. ${ }^{13}$ Remarkably, the main factor responsible for complications during FB is sedation, which is usually associated with an obstruction at oropharynx level. This concept has been translated in our study into a higher requirement for insertion of a naso- or oropharyngeal airway

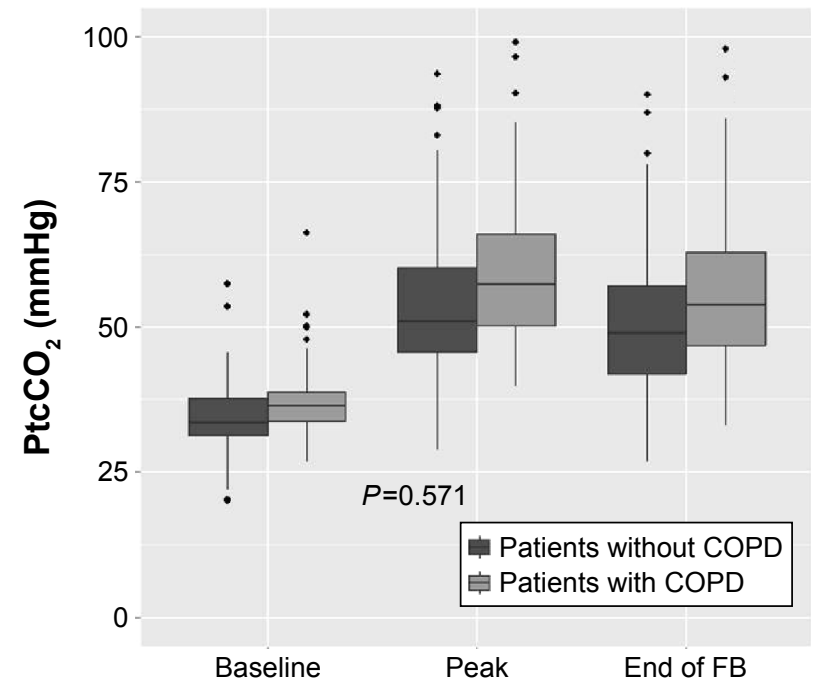

Figure 3 Transcutaneous carbon dioxide tension in a nested-cohort of 220 patients undergoing flexible bronchoscopy based on the presence or absence of COPD. Black boxes represent patients without COPD and gray boxes represent patients with COPD.

Abbreviations: $\mathrm{FB}$, flexible bronchoscopy; $\mathrm{PtcCO}_{2}$, transcutaneous carbon dioxide tension. in patients with COPD, which was, however, dependent on the age and duration of the procedure. Accordingly, the incidence of sedation-associated complications is likely to be influenced by different variables other than airflow obstruction. It is well known, for instance, that patients with advanced oncologic and hematological disease - including solid organ and bone marrow transplantation - have a higher incidence of complications during bronchoscopy. ${ }^{18}$ In addition, the most frequently encountered severe complication was major bleeding which is clearly associated with more invasive bronchoscopy procedures but unrelated to the extent of airflow obstruction.

Hypotension is a well-known side effect of propofol during induction of anesthesia, with an incidence ranging from $25 \%$ to $67.5 \%$ irrespective of the presence of cardiovascular conditions. ${ }^{19}$ Similar hypotensive effects have been reported in sedation related to bronchoscopy. ${ }^{12,13}$ Hypotension following propofol is suggested to be caused by a decrease in sympathetic activity comprising a reduction in systemic vascular resistance and decline in cardiac output linked to vasodilation, diminished baroreflex mechanism, and decreased myocardial contractility. ${ }^{20}$ It is conceivable that the higher incidence of hypotension observed in this study might be related to the advanced age and cardiovascular comorbidities more commonly present in the group of patients with COPD.

The incidence of hypoxemia on at least one occasion during bronchoscopy has been reported to range between $29 \%$ and $35 \%{ }^{9}, 10,14$ While the incidence of hypoxemia, defined as oxygen desaturation $\leq 90 \%$ of any duration, was similar in both groups in the current study, patients with COPD had a longer time with an oxygen saturation below $88 \%$ and a lower nadir oxygen saturation during examination. These findings are not surprising as patients with COPD had lower baseline saturation. Indeed, as pulmonary function deteriorates, and 
as the disease progresses, the risk of alveolar hypoxia and consequent hypoxemia increases. ${ }^{1}$ Accordingly, over $80 \%$ of the patients with advanced disease enrolled in the National Emphysema Treatment Trial were using some form of oxygen therapy. ${ }^{21}$ Of note, COPD was an independent factor associated with the need of invasive ventilator support in critically ill patients with acute respiratory failure undergoing flexible bronchoscopy in a previous study. ${ }^{22}$

While propofol sedation did not cause excessive respiratory drive depression in patients without COPD,${ }^{23}$ bronchoscopy performed under moderate sedation in patients with severe COPD was frequently associated with significant hypoventilation as detected by transcutaneous $\mathrm{PtcCO}_{2}{ }^{6}$ Therefore, it is tempting to speculate that, despite the similar increase in $\mathrm{PtcCO}_{2}$ in patients with and without COPD observed in our study, patients with COPD may be at higher risk for complications due to the elevated $\mathrm{PtcCO}_{2}$ baseline levels. The question whether transcutaneous $\mathrm{CO}_{2}$ monitoring can improve patient safety in patients with severe airflow obstruction may warrant further evaluation.

We acknowledge several limitations of the present study. This was a monocentric study performed in an institution in which the endoscopy nursing staff have considerable expertise on propofol sedation. Hence, caution might be needed when introducing this sedative regimen in other institutions. The study was not non-blinded and, potentially, this may represent a source of bias. However, outcomes of interest were objective and predefined. Although both patient groups presented distinct baseline characteristics, differences between the two groups in terms of demographics as well as lung function reflect the inhered characteristics of the disease rather than a real imbalance between the groups. We have applied the GOLD definition of COPD to categorize patients in both diagnostic groups. Importantly, 242 (37\%) of the patients categorized as non-COPD due to the presence of an alternative, more probable diagnosis for the obstructive pattern in lung function had $\mathrm{FEV}_{1} / \mathrm{FVC}<70$. This figure highlights the fact that there are many different pathological entities associated with an obstructive pattern in the lung function test. While the GOLD definition is far from ideal, it remains the most commonly used to diagnose the disease, having, therefore, the greatest generalizability. It is possible, however, that the use of more refined diagnostic criteria could have led to different results. Nevertheless, in this study, the risk of complications and the number of complications were similar in patients with and without obstruction, irrespective of the COPD diagnosis. The investigation of the pathophysiological mechanisms associated with hypoxemia during FB in patients with COPD was out of the scope of the current study. As previously described, the principal contributor to hypoxemia in COPD patients seems to be ventilation/ perfusion $(\mathrm{V} / \mathrm{Q})$ mismatch resulting from progressive airflow limitation and emphysematous destruction of the pulmonary capillary bed. Increased tissue consumption of oxygen, with resultant decreased mixed venous oxygen tension also appears to contribute to increased hypoxemia during exacerbations. The risk of sleep-disordered breathing and consequent nocturnal hypoxemia, potentially exacerbated during sedation, correlates with the degree of obesity, which is increasingly reported in patients with COPD. Dysregulated ventilatory control is another factor contributing to the occurrence and persistence of hypoxemia in COPD. In addition, alveolar hypoxia is associated with the development of pulmonary hypertension in patients with COPD. Skeletal muscle dysfunction is another relevant extrapulmonary consequence of COPD and might also be linked to hypoxemia. ${ }^{1}$ The strengths of study are its originality, the case-control design with a large sample size, and the objective assessment of the disease and its severity, including the complexity of bronchoscopic procedures.

\section{Conclusion}

In conclusion, our data suggest a similar safety profile of flexible bronchoscopy using moderate propofol sedation in patients with and without COPD. This finding confirms the suitability of the procedure for both clinical and research indications.

\section{Acknowledgments}

We thank the endoscopy staff, particularly EP, and Anja Meyer RN for the support during the trial. We also thank Andy Schötzau and Christian Müller (Eudox AG) for statistical analyses. Daiana Stolz was supported by grants from the Swiss National Foundation (PP00P3_128412/1). Additional funding was provided by the Clinic of Pulmonary Medicine and Respiratory Cell Research, University Hospital Basel.

Some of the data of this manuscript have been honored with an oral presentation at the Chest Conference 2015, Montreal, Canada.

\section{Author contributions}

All authors contributed toward data analysis, drafting and critically revising the paper, gave final approval of the version to be published, and agree to be accountable for all aspects of the work. 


\section{Disclosure}

The authors report no conflicts of interest in this work.

\section{References}

1. Kent BD, Mitchell PD, McNicholas WT. Hypoxemia in patients with COPD: cause, effects, and disease progression. Int J Chron Obstruct Pulmon Dis. 2011;6:199-208.

2. Hirsch FR, Scagliotti GV, Mulshine JL, et al. Lung cancer: current therapies and new targeted treatments. Lancet. Epub 2016 Aug 26.

3. Shen P, Morissette MC, Vanderstocken G, et al. Cigarette smoke attenuates the nasal host response to Streptococcus pneumoniae and predisposes to invasive pneumococcal disease in Mice. Infect Immun. 2016;84(5):1536-1547.

4. Stolz D, Pollak V, Chhajed PN, Gysin C, Pflimlin E, Tamm M. A randomized, placebo-controlled trial of bronchodilators for bronchoscopy in patients with COPD. Chest. 2007;131(3):765-772.

5. Hattotuwa K, Gamble EA, O’Shaughnessy T, Jeffery PK, Barnes NC. Safety of bronchoscopy, biopsy, and BAL in research patients with COPD. Chest. 2002;122(6):1909-1912.

6. Fruchter O, Carmi U, Ingenito EP, Refaeli Y, Kramer MR. Transcutaneous carbon dioxide in severe COPD patients during bronchoscopic lung volume reduction. Respir Med. 2011;105(4):602-607.

7. Du Rand IA, Blaikley J, Booton R, et al; British Thoracic Society Bronchoscopy Guideline Group. British Thoracic Society guideline for diagnostic flexible bronchoscopy in adults: accredited by NICE. Thorax. 2013;68(Suppl 1):i1-i44.

8. Wahidi MM, Jain P, Jantz M, et al. American College of Chest Physicians consensus statement on the use of topical anesthesia, analgesia, and sedation during flexible bronchoscopy in adult patients. Chest. 2011;140(5):1342-1350

9. Stolz D, Kurer G, Meyer A, et al. Propofol versus combined sedation in flexible bronchoscopy: a randomised non-inferiority trial. Eur Respir $J$. 2009;34(5):1024-1030.

10. Clark G, Licker M, Younossian AB, et al. Titrated sedation with propofol or midazolam for flexible bronchoscopy: a randomised trial. Eur Respir J. 2009;34(6):1277-1283.

11. Bosslet GT, Devito ML, Lahm T, Sheski FD, Mathur PN. Nurseadministered propofol sedation: feasibility and safety in bronchoscopy. Respiration. 2010;79(4):315-321.
12. Grendelmeier P, Kurer G, Pflimlin E, Tamm M, Stolz D. Feasibility and safety of propofol sedation in flexible bronchoscopy. Swiss Med Wkly. 2011;141:w13248.

13. Grendelmeier P, Tamm M, Pflimlin E, Stolz D. Propofol sedation for flexible bronchoscopy: a randomised, noninferiority trial. Eur Respir J. 2014;43(2):591-601.

14. Schlatter L, Pflimlin E, Fehrke B, Meyer A, Tamm M, Stolz D. Propofol versus propofol plus hydrocodone for flexible bronchoscopy: a randomised study. Eur Respir J. 2011;38(3):529-537.

15. Du Rand IA, Barber PV, Goldring J, et al; British Thoracic Society Interventional Bronchoscopy Guideline Group. British Thoracic Society guideline for advanced diagnostic and therapeutic flexible bronchoscopy in adults. Thorax. 2011;66(Suppl 3):iii1-iii21.

16. Chhajed PN, Glanville AR. Management of hypoxemia during flexible bronchoscopy. Clin Chest Med. 2003;24(3):511-516.

17. Heuss LT, Schnieper P, Drewe J, Pflimlin E, Beglinger C. Safety of propofol for conscious sedation during endoscopic procedures in high-risk patients-a prospective, controlled study. Am J Gastroenterol. 2003;98(8):1751-1757.

18. White P, Bonacum JT, Miller CB. Utility of fiberoptic bronchoscopy in bone marrow transplant patients. Bone Marrow Transplant. 1997;20(8): 681-687.

19. Claeys MA, Gepts E, Camu F. Haemodynamic changes during anaesthesia induced and maintained with propofol. Br J Anaesth. 1988; 60(1):3-9.

20. Farhan M, Hoda MQ, Ullah H. Prevention of hypotension associated with the induction dose of propofol: a randomized controlled trial comparing equipotent doses of phenylephrine and ephedrine. J Anaesthesiol Clin Pharmacol. 2015;31(4):526-530.

21. Martinez FJ, Foster G, Curtis JL, et al; NETT Research Group. Predictors of mortality in patients with emphysema and severe airflow obstruction. Am J Respir Crit Care Med. 2006;173(12):1326-1334.

22. Cracco C, Fartoukh M, Prodanovic H, et al. Safety of performing fiberoptic bronchoscopy in critically ill hypoxemic patients with acute respiratory failure. Intensive Care Med. 2013;39(1):45-52.

23. Carmi U, Kramer MR, Zemtzov D, Rosengarten D, Fruchter O. Propofol safety in bronchoscopy: prospective randomized trial using transcutaneous carbon dioxide tension monitoring. Respiration. 2011; 82(6):515-521.
International Journal of COPD

\section{Publish your work in this journal}

The International Journal of COPD is an international, peer-reviewed journal of therapeutics and pharmacology focusing on concise rapid reporting of clinical studies and reviews in COPD. Special focus is given to the pathophysiological processes underlying the disease, intervention programs, patient focused education, and self management protocols.

\section{Dovepress}

This journal is indexed on PubMed Central, MedLine and CAS. The manuscript management system is completely online and includes a very quick and fair peer-review system, which is all easy to use. Visit $\mathrm{http}: / / \mathrm{www}$. dovepress.com/testimonials.php to read real quotes from published authors. 